\title{
CSR within Large Retailers International Supply Chains*
}

\author{
Fabio Musso $^{* *}$, Mario Risso ${ }^{* * *}$
}

\begin{abstract}
CSR has become important in terms of consumers' perceptions, so it has become important for all consumer-oriented firms. Companies have increased their levels of ethical and social responsibility by implementing methodologies linked to CSR initiatives.

Particularly in the retail sector, large international retailers are investing heavily to cope with the ethical demands of consumers and increase their own awareness of CSR issues.

However, retailers are often channel leaders and control various activities in the supply chain and they tend to be more able to adopt active roles in leading international supply chains to follow a CSR approach.
\end{abstract}

Keywords: Corporate Social Responsibility; Large Retailers; Global Markets; Ethical Products; Fair Trade Products; Global Supply Chains; Codes of Conducts in Retail Procurement: Coin and H\&M Cases

\section{Corporate Social Responsibility and Global Markets}

An increasing interest in ethical issues such as Corporate Social Responsibility (CSR) and its environmental and social implications related to relationships between firms and consumers has been well investigated by various existing studies (Dagnoli, 1991; Shaw e Clarke, 1999; Shaw e Shui, 2001; Caselli, 2003; Pepe, 2003; Maignan e Ferrel, 2004). In the last few decades, ethics in business activities has become part of the wider concept of CSR, which is developing from a good idea to a critical part of business activity. In particular, CSR has become important in terms of consumers' perceptions, so it has become important for all consumer-oriented firms.

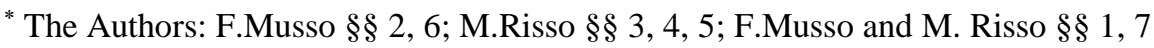

** Associate Professor of International Marketing, University of Urbino-Carlo Bo (fabio.musso @uniurb.it)

*** Assistant Professor of Management, University of Rome-Tor Vergata (mario.risso@ uniroma2.it)
}

Edited by: ISTEI - University of Milan-Bicocca

ISSN: 1593-0319

Musso Fabio, Risso Mario, CSR within Large Retailers International Supply Chains, Symphonya. Emerging Issues in Management (symphonya.unimib.it), n. 1, 2006, pp. 79-92

http://dx.doi.org/10.4468/2006.1.06musso.risso 
Today's aware, educated consumers are not only interested in new products; they also want to know more about the companies that produce these products, the labour conditions under which they were produced, and how their production impacts the environment and economic growth of the local communities along the companies' supply chains (Strong, 1996; Shaw and Clarke, 1998, Harrison et al., 2005).. As consumers become more aware of ethical behaviours, their motivation is increasingly toward a balance between personal and social benefits (Macchiette and Roy, 1994; Hemingway and Maclagan, 2004). In response, companies have increased their levels of ethical and social responsibility by implementing methodologies linked to CSR initiatives. Extant debates in the literature have found a positive correlation between clear CSR and business performance (Balabanis et al., 1998).

Recently, the importance of CSR has increased in all economic sectors. Particularly in the retail sector, large international retailers are investing heavily to cope with the ethical demands of consumers and increase their own awareness of CSR issues (Whysall, 2000; Jones e al., 2005).. Key international retailers have begun to offer some ethical products, consolidating their approach to CSR through offers related to sustainable development and greater fairness in terms of distribution of benefits among all actors in the supply chain. Completely restructuring their offers in an ethical way, some retailers have gained a competitive advantage. Such is the case with US retailer Wholefoods, which has characterized its assortments with organic products and products manufactured using a sustainable approach (Eurostaf, 2001).

However, consumers seem less critical of retailers than they are of big manufacturers; consumers perceive retailers as being only partially responsible for the activities of whole supply chains and tend to be more trusting of retailers' business behaviours. Retailers' image is more positive and more easily linked to social issues because they are naturally closer to consumers' communities, whereas manufacturers often operate 'out there' in someone else's community. However, because retailers are often channel leaders and control various activities in the supply chain, they tend to be more capable of adopting active roles in leading international supply chains to follow a CSR approach. Most innovative retailers have capitalized on this opportunity and have begun to manage their offers and marketing policies through implementation of extra-economic value in all activities and relationships with all supply chain actors.

This article discusses the role of ethics and the CSR approaches of retailers in the management of international supply chains. In particular, it illustrates policies and tools adopted by firms that have implemented a CSR approach to managing supply chain relationships.

\section{CSR, Large Retailers and International Supply Chains}

In the literature, several studies have been concerned with corporate ethics and corporate responsibility, and several have investigated the importance of ethics in the buying and selling activities of industrial companies (Redelius and Bucholz, 1979; Dubinsky and Gwinn, 1981; Trawick et al., 1988; Wood, 1995). However, fewer 
studies have explored the importance of ethics in the buyer-seller relationships of retail companies (Dickerson and Dalecki, 1991; Arbuthnot, 1997; Musso 1999). Recently, the boundaries of the classic concept of business ethics have widened, entering the broader realm of CSR and sustainable development. Indeed, the expression 'sustainable development' synthesizes the three dimensions of the problem: safeguarding the environment, respect for human rights, and fairness in the redistribution of benefit among all actors in the supply chain. Based on this concept, the vertical alignment of the supply chain is overwritten by the horizontal one that is generated by communities and local areas.

Authors of extant studies on CSR and supply chains have focused mainly on multinational industrial corporations, often leaders of complex and articulated supply chains (Carter, 2000; Park and Stoel, 2005; Mamic, 2005; Maloni and Brown, 2006). Therefore, some of these contributions have considered CSR implications in the national and international marketing activities of retail companies (Nicholls, 2002; Pepe, 2003; Jones et al, 2005). Others have analyzed individual and shared responsibilities among all supply chain actors (producers, retailers, consumers), particularly in terms of relationships between companies in the North and the South of the world.

The 'sustainable development' issue and the linked responsibilities of the economic and social operators have been well addressed. Ethical, social and environmental values have been considered using a comprehensive approach that includes not only the task environments of the firms but all steps along the chain of productiondistribution-consume. Human rights, fair distribution of benefits and attention to the environment are considered in relation to communities' needs and the areas where the different phases of the supply chain are realized: upstream, at the origin of the supply chain, where a fair distribution of benefit permits a balanced development of the local societies, and downstream in the final markets, where products are sold to meet the demands of consumers to be more ethical.

The supply chain is a critical system in which it is possible to evaluate and allocate strategies related to the concept of responsibility. In those supply chains where the individual phases can be managed in a coordinated way via a channel leader, it is useful to understand the specific role of each actor. In particular, it is useful to analyze the business activities of retailers, especially when the retailer is a large company, because of its ability to influence consumers while ruling the whole supply chain. Large retailers play a dominant role in controlling sustainable development of the production and distribution processes of their products for several reasons. Retailers have substantial economic weight and ability to rule and generate ex-novo supply chains. Thus, large retailers are controllers and guarantors of the entire value chain, particularly for the retailer's own brand products, which directly affect its corporate image. On the other hand, because retailers are physically close to consumers, they understand the market's demands, receive new consumer requests directly from the consumer, and can activate retail marketing tools that are based on local needs, as well as extra-economic needs. Thus, retailers are the first receivers of requests for more ethical and responsible approaches to managing products and, at the same time, they are able to take an active role in addressing consumer behaviours in terms of their ability to control ethical and social issues. Consequently, retailers tend to have more power than producers do and 
often become privileged centres of value accumulation and filters for information flow in the supply chain.

In particular, the retailer, where possible, exerts its channel leadership to manage 'captive' supply chains. In these supply chains, the retailer has broad power not enjoyed by small suppliers that cannot support the cost of changing customers or accessing new markets (Gereffi e al., 2005). Thus, supply chains are frequently characterized by a high degree of monitoring and control by the retailer. In this way, the retailer becomes the most important part of the supply chains because:

1. the retailer exerts control and augments its contractual power over suppliers, even in relation to traceability laws; this control increases the retailer's power to re-construct and coordinate the supply chain;

2. the retailer enhances the diffusion of private-label (own-brand) products and directly steers ideation, production and trade, leading to the retailer's natural channel leadership;

3. the retailer tends to search for short supply chains in order to gain higher margins and develop marketing policies closer to its business; this effort increases its power.

The combination of retailers' characteristics, the retail market's characteristics, and new consumer sensitivities encourages innovative retailers, particularly in advanced countries such as the UK and northern European countries, to adopt a CSR approach that characterizes the retail offer. Many retailers write a CSR Company Report as testimony of their responsible behaviour, and some retailers (e.g., Ikea, H\&M, Coin) have adopted a code of conduct in order to discipline working conditions and safeguard the environment. Other innovative retailers link their products to respect for the environment and for social and ethical values and to having been produced through Fair Trade circuits or by conventional circuits specifically adapted for the CSR products.

For retailers, social and environmental issues are not related only to products and corporate images. Unlike industrial companies, retailers manage a complex formula that consists of products, services, point of purchase (store) and consumer experiences offered to the customer. For consumers, buying products is not only a purchase experience; the relationship retailer-consumer is direct, and store loyalty can be more effective than brand loyalty. For consumers, a retailer's social responsibility is closely related to its business activity, so CSR is more necessary for retailers than any other sector to maintaining competitiveness.

CSR is related to a wide range of business activities, from product and supplier selection to promotional activities and the inclusion, by some innovative retailers, of the concept of ethical and social sustainability in the brand and in all key activities of the retail business.

By adopting CSR, retailers can more quickly and effectively achieve several goals:

- market differentiation (Piacentini et al., 2000);

- enhanced word-of-mouth and reduction in marketing investments;

- customer and worker loyalty (Pepe, 2003);

- eligibility for inclusion in a stock-market index that includes only those companies deemed to be socially responsible. 
The competition among large retailers brings them to search solutions capable of improving customer relationships and, consequently, company performance. New coordination, optimization and visibility efforts can be assigned to activities related to production, distribution and supply of products and services, which all converge in the shop or storefront. According to Pepe (2003), in the shop, customers meet their material and immaterial needs for products, and demonstrate their buying behaviour, life-styles, individual and shared values, which are related one to the others, so the shop opens itself to various possibilities of different composition. In this way, retail marketing finds vital reasons to get stronger and renovate itself, multiplying the potential for positioning and playing with new elements.

\section{Introduction of Codes of Conducts in Retail Procurement: the Cases of Coin and H\&M}

CSR involves a wide range of activities, from products and supplier selection to promotional activities and company policies; in large retailers, CSR includes the concept of ethical and social sustainability in the brands and in all key activities of the retail business.

CSR in large retailers is present in relation to:

- the increasing sensibility of consumers and the new marketing frontiers that are connected to relational and experiential dimensions; this convergence results in a meeting between the customer and the point of sale whereby the retailer offers a mix of products-services-value to customers that considers their land and culture;

- the promotion of the retailer's relationship with small and medium suppliers as one that is more committed and collaborative (Pepe, Musso, 2000);

- the management of the relationship with local and international institutions that facilitate and sustain firms involved in social and environmental activities;

- adoption of a code of conduct that identifies labour, safety, environmental and social standards for all operators to follow in their activities in response to the attention paid to these issues by the community where the company operates (Roberts, 2003; Logsdon e Wood, 2005).

Large retailers adhere to control procedures in their production processes (also identified at the international level, such as in the case of Chiquita and the code of SA 8000) and integrate into these procedures an analysis of the social and environmental sustainability of their suppliers. The procurement procedures of the Coin Group (Italian fashion retailers) and H\&M international clothing retailer provide illustrative examples of implementation of CSR activities.

The Sourcing and Supply Department of the Coin Group identifies a list of suppliers that adhere to the Coin code of conduct. In this way, Coin encourages its suppliers to develop policies and behaviours in compliance with universal values such as human rights, labour rights and respect for the environment. The Coin Group's suppliers must warrant their respect for the rules, even from their subsuppliers. The Coin Group periodically uses audits by Intertek, an international 
operator for certification, to verify their suppliers' compliance with these conditions. The Coin Group uses suppliers from different countries, based on its business needs, but the suppliers are scored from 1 to 5 based on their compliance with elements that reflect cost, speed, proximity, flexibility and social standards (Table 1).

Table 1: Analisys Factors Adopted by Coin for Suppliers/Countries Evaluation

\begin{tabular}{|l|c|c|c|c|c|c|c|c|c|c|}
\hline \multicolumn{8}{|c|}{ Bangladesh is the chepest, Turkey the most flexible country } \\
\hline & & & & & & & & & \\
\hline & Speed & Costs & Quality & Scalability & SupportExpertise & Reliability & Communication & Flexibility & Proximity & Social Standards \\
\hline & & & & & & & & & & \\
\hline China & 3,3 & 4,3 & 3,9 & 3,2 & 3,2 & 3,6 & 3,4 & 2,8 & 2,3 & 3,5 \\
\hline India & 2,6 & 3,8 & 3,4 & 2,7 & 3,0 & 2,6 & 3,1 & 3,3 & 2,4 & 2,9 \\
\hline Bangladesh & 2,8 & 4,8 & 3,1 & 2,8 & 2,4 & 2,9 & 2,5 & 2,8 & 2,3 & 2,4 \\
\hline Asia-Developing & 2,0 & 4,3 & 3,3 & 2,7 & 2,1 & 2,8 & 2,6 & 2,4 & 2,3 & 2,6 \\
\hline Asia-Developed & 2,9 & 3,6 & 3,9 & 3,0 & 3,1 & 3,4 & 3,4 & 3,1 & 2,8 & 3,1 \\
\hline Turkey & 4,3 & 2,4 & 4,1 & 3,6 & 4,2 & 3,6 & 3,7 & 4,3 & 3,9 & 4,1 \\
\hline Africa & 3,3 & 2,7 & 3 & 2,7 & 2,3 & 2,7 & 2,7 & 3,0 & 2,7 & 3,3 \\
\hline Eastern Europe & 4,1 & 3,1 & 3,8 & 3,3 & 3,4 & 3,4 & 3,3 & 3,8 & 3,7 & 3,6 \\
\hline Western Europe & 4,4 & 1,6 & 4,4 & 3,6 & 4,3 & 4,1 & 4,0 & 4,1 & 4,6 & 4,9 \\
\hline
\end{tabular}

Source: Coin Group, Company data

H\&M buys clothing items and others products from over 700 independent suppliers from all over Asia. All H\&M suppliers are required to meet certain obligations concerning the production of their goods, including working conditions and environmental rules. H\&M's buying office plans the assortment of products to be bought and then delegates its twenty worldwide production offices to formulate the orders and choose suppliers based on the right balance between price and quality. Workers in the local production offices are locals in order to facilitate relationships with suppliers. Production offices conduct a number of quality tests, but they also verify working conditions in the factories and the safety and quality of goods. Each supplier must underwrite H\&M's code of conduct, which includes requirements involving respect for workers, the environment, animals and customers. If local norms and legislation are stronger than what is outlined in its code of conduct, H\&M requires its suppliers to comply with local requirements and to have all the necessary permits and licences for their activities.

In relation to social rights, H\&M's code of conduct is based on the UN Convention on the Rights of the Child and the International Labour Organization (ILO) conventions on working conditions and rights of workers. In particular, the H\&M's Code includes requirements concerning the working environment, fire safety, working hours, wages, and freedom of association; and bans child labour (supported through collaboration with international institutions such as UNICEF), gender discrimination, and forced work. By considering the conditions of the workers in local factories, H\&M contributes to improving the culture for work relationships at the socio-economic level in the countries where the suppliers' factories are located.

In 2006 H\&M undertook a 'Business for Social Responsibility' project, and the obligation for suppliers became stricter. Controls and tests are conducted to verify both the production processes and products. In relation to the use of chemical substances, all suppliers 
must sign a formal agreement (H\&M's Chemical Restrictions) and a special agreement for cosmetics (H\&M Cosmetics Restrictions).

These compliance requirements apply only to suppliers directly connected to $\mathrm{H} \& \mathrm{M}$, so there are no controls on the previous steps of the supply chain (e.g., the production of raw material, textiles or plants). To cope with this situation, H\&M entered into the FAP (Full Audit Programme) initiative, which facilitates the monitoring of subcontractors. Even the protection of animals is considered in H\&M's code of conduct, and strict expectations are provided for suppliers. In particular, H\&M does not sell real fur but only leather from sheep, pigs, goats and cattle that have been bred for meat production, not just for their skin. No other leather is permitted in products sold by H\&M. No animal testing is carried out on its cosmetics products, either during production or for the finished products.

\section{The Institutional Solutions for CSR in Supply Relationships}

A further development in retailers' commitment to promoting CSR in supply relations is the joint initiatives with NGOs and philanthropic organizations that operate primarily in the Far East. Both $H \& M$ and the Carrefour Group, for example, are driving in this direction. $\mathrm{H} \& \mathrm{M}$ is operating with agreements with the UN, UNICEF, Amnesty Business Group, Water Aid and the Fair Labor Association, while the Carrefour Group is operating with the FIDH (Fédération Internationale des Droits de l'Homme). From 2004 to 2006, the Carrefour Group carried out a pilot project aimed at creating operating conditions that would respect the human rights of Bangladesh suppliers' employees.

Retailers' efforts to draw up a uniform international standard to promote respect for environmental and social issues are of particular interest. In this case the CIES (Comité International d'Entreprises à Succursales) is emerging as an association of major retailers and worldwide brand manufacturers working to improve the performances of their members. Its mission is to promote best practices and common positions on non-competitive strategic issues, such those related to CSR. The CIES provides a valuable platform for distributors who want to work together to develop more efficient systems for the supply chain management and relationships with suppliers. In the past, the CIES successfully promoted the Global Food Safety Initiative to harmonize food production systems (Pepe, 2003). More recently, in 2006, it facilitated the development of the Global Social Compliance Program (GSCP), which was founded by the world's largest retailers (Wal-Mart, Carrefour, Tesco, Migros, and Metro) and was open to brand manufacturers with the aim of improving working conditions in international supply chains. The GSCP provides a platform on which to build consistency and consensus on best practices in labour standards within international supply chains, in order to develop a unique approach of suppliers who work with retailers all over the world.

Among the reasons that led to the birth of GSCP was the need to rationalize investments in CSR by major retailers. The GSCP has made considerable efforts to develop conduct codes; however, these codes were structured according to different 
guidelines so duplications, confusion among suppliers and overall inefficiencies occurred.

The objective of the GSCP, by pursuing continuous improvement of working conditions worldwide, is to adopt a system of comparison and mutual transparency to guide operators towards convergence of standards. In this way, retailers and their international suppliers can focus on the main causes of non-compliance with standards and find common solutions. To achieve this goal, the GSCP is building a set of tools $-\mathrm{a}$ code of conduct, an audit checklist, an audit methodology, and an auditing standard that aim to identify and then propose best practices to be followed in channel relations. The program aims to develop these instruments through working groups of experts whose task is to identify best practices and build consensus around them. Companies can partially or totally integrate this toolkit into their existing systems or use it as references for comparison. It is the intention of the organizers that all the instruments be openly available to any company that wishes to use them.

The focus of the GSCP is limited to working conditions because of the difficulty in using the same methodologies with reference to other aspects of business operations, such as respect for the environment. In such cases a deep change would involve the audit process, methods and auditors.

With the establishment of the GSCP, major retailers and brand manufacturers want to stimulate mutual learning and to accelerate control of working conditions among suppliers worldwide. At the same time, the GSCP platform facilitates the development of better and longer-lasting relationships with suppliers. Codifying standards can promote commitment to improving working conditions through the use of common and non-divergent tools, thus avoiding the excessive variety of codes of conduct that can lead suppliers to waste energy. The GSCP aims to create social standards for all food sold by large retailers. In the future, its goal is to incorporate even non-food goods, such as toys, electronics, clothing, and household goods.

\section{The Offer of Ethical Products}

In some cases, retailers' attitudes toward CSR can be even more resolute and innovative, and some retailers promote or directly organize supply chains of products that are approved and certified by fair trade organizations. Some large retailers, having gained the customers' confidence, also get to the point of selfcertifying their supply chains.

The increased importance assigned by retailers to ethical and social issues leads some of them to broaden their assortment of private-label fair trade products. In some cases, if the offer's differentiation is aimed at customers who do not yet have a deep ethical awareness, retailers are likely to build a range of private-label products through their own networks according to the principles of fair trade, but without using the certification and the control procedures of Fair Labeling Organizations (FLO) ${ }^{1}$. In this way, retailers can improve their positioning by adding ethical values to their brand while, at the same time, remaining free to manage their own supply chains and avoid the royalties and the reporting requirements of certification bodies. 
In other cases, especially where retailers feel the pressure of the media, of the organizations of fair trade and of consumers who have a greater awareness of the social-ethical issues related to products, retailers may choose to label their ownbrand products with FLO certifications. Usually, retailers' private-label products can be sold with the FLO certification together with other private-label fair trade products that don't have any certification, even if they are coming from Alternative Trade Organizations (ATO) ${ }^{2}$. In addition, where appropriate, retailers may have an assortment of private-lable fair trade products that are certified by FLO and selfcertified. The presence of different types of fair trade products draws the consumer's attention to the category and provides more opportunities to improve marketing policies associated with it.

The main examples of retailers that operate according to this strategy are Marks \& Spencer, Coop Italia, Tesco plc and, more recently, Carrefour. They now offer not only wide assortments of fair trade products in their stores, but also their own brands assortments coming from supply chains that are directly controlled and managed in tight relations with small and medium-sized producers from the less developed countries of the world.

\section{New Social Responsibility Leadership within Global Supply Chains}

Retailers develop CSR methodologies in supply chain management by adopting ethic codes and ethic standards in the selection/coordination of suppliers (mostly among less developed countries' manufacturers) and by introducing a number of private-label ethical products whose supply chains are strictly controlled. This new approach often requires a reorganization of operative structures inside retailers' buying offices, in particular as regards supplier-selection criteria. Nevertheless, only a few cases show a real respect for CSR principles; most initiatives are just window-dressing and are limited to the more visible aspects of CSR in order to impress consumers.

In particular, in the case of products listed as fair trade products, particularly private-label products, retailers' approaches vary. Fair trade products coming from ATOs are managed with prevailing criteria related to profitability and differentiation of assortments. Single goods are dealt with by respective buyers or category managers. Only in cases where a fair trade products category is created, a specific buying unit is established.

Private-label fair trade products are managed in two ways. In the first way, a retailer has a wide category of products, of which fair trade products are a part. In this case, fair trade products play only an economic role for increasing sales and improving category profitability. In the second way, which is the prevailing case, fair trade products play a more important role, aiming to generate for the final customer a perceived mix of economic, social, ethical, environmental and emotional value, even if with lower revenues. The product becomes a symbol of the fascia identity and positioning. In this case, there is a staff structure supporting the responsibilities of buying activities by buyers or category managers that help 
them to integrate the sub-category of fair trade products within the overall category. This is the model previously applied to other sub-brand products, like organic food and ecological products.

Main investments related to the introduction of fair trade product lines are at the organizational level because of the need to organize, coordinate and control the supply chain. Most of the time, suppliers are international and from less developed countries, increasing costs and difficulties in coordination.

Retailers follow one or a combination of two main methods to organize their supply chains. The first method is based on the supporting activity to fair trade operators, voluntary groups, and non-governmental organizations (NGOs) that help retailers in structuring and organizing the supply chain for fair trade products, bringing in their different cultures, values and management principles. This method can bring in more ethical guaranties to the construction and management of the supply chain, but it requires an effort from the retailer to mediate and combine the relational and managerial capabilities of very heterogeneous partners.

The second method refers to a reorganization of the retailer's existing supply chains according to fair trade principles and standards. This method is being more frequently adopted by larger retailers for supply chain management of their fair trade private-label products, like bananas for Sainsbury, cotton apparel for Marks \& Spencer and some food products for Coop Italia. This method is more convenient for retailers because of the lower costs of supply chain reorganization and because there is a more sales potential for private-label products that combine fair trade values with other ethical value, like organic and ecological characteristics. These kinds of value contribute to increasing the overall turnover of the fair trade products category.

Both methods accommodate the gradually changing role of supplier manufacturers. The ethic nature of fair trade supply chains stimulates a different approach to retailer-supplier relationship. The negative effects of distance and lack of communication that characterizes relations with suppliers from the South of the world (enforced by the presence of international intermediaries) are reduced. In addition, the shorter supply chain and a different cultural basis in the channel relation between the channel leader (retailer) and small suppliers from the South will lead to better reciprocal comprehension and adaptation and a more cooperative relationship.

Managing fair trade supply chains, either those that use fair trade operators or those that are directly coordinated by retailers, helps retail managers understand the local conditions in which small suppliers operate. This understanding broadens the possibilities for improving the relationship and developing best practices according to fair trade principles that are not limited to formal declarations and labelling actions.

The application of fair trade criteria can lead to many positive changes in retailers' buying organizations, in particular as they relate to the supply chain structure, relational processes, the climate of negotiation and the level of commitment. Cooperative factors become more relevant in relationships with small suppliers, and a long-term perspective prevails. In general, a more systemic approach can emerge with the involvement of institutional bodies at the local, national and international levels, where professionals and operators bring 
complementary competencies to finance, logistics, standard systems and certifications. According to Pepe, the supply chain economy needs to function as a whole, involving partners from different cultures that can contribute to generate a higher level of collective culture, as a result of complementary economic, ethical and ecological values.

With the introduction of a CSR method within retailers supply chains, new networks based on ethical-social values are organized with the characteristics of:

- greater emphasis on cooperative issues, supported by a commitment to knowledge, experience and innovative capabilities exchange;

- lower importance of hierarchical issues and more balanced power basis within negotiations, together with more increased relational capabilities of smaller manufacturers that are also increasingly capable of finding alternative channels for their products and improving their competencies;

- greater possibility to obtain a more effective supply network with shorter buying channels, costs savings and more rapid adaptations of assortments to final demand needs and changes;

- the introduction of relational criteria in which individuals maintain a central role, addressing communication, logistical and coordination processes towards respecting people;

- the possibility to pursue a development model for relationships and supply processes with a balanced role for all partners, with more guarantees for workers and more attention paid to environment and local social issues.

All these characteristics drive towards a virtuous cycle that can be activated to stimulate a cooperative network in which a more balanced development process and a more equal distribution of benefits can be obtained.

\section{CSR, Fair Trade Products and Global Markets}

The adoption of CSR guidelines by large retailers, including standards for manufacturing and relational processes and the introduction of fair trade products in their assortments, provides an opportunity to combine ethical-social principles with the profitability goals of retailers. The experiences of some major retailers show that these two goals are compatible through a change in the corporate culture that is not limited to the formal aspects of processes. Adopting CSR guidelines and changing the corporate culture can stimulate a new approach to international trade relations that features a higher level of cooperation and a more equal distribution of benefits between more developed countries and those in the South of the world.

Even if ethical, ecological and social principles can have more influence in managing international supply chains, large retailers need to maintain their efforts to meet market and profitability objectives. In most cases, CSR initiatives, including fair trade product offerings, are adopted to increase profitability or improve a reputation for social-ethical sensitivity. This approach is becoming more important as consumers' awareness of ethical issues and the negative opinion of a large fascia of consumers regarding globalization processes increase. 
Most recent investments by retailers in marketing activities have been addressed to stimulate consumers' perceptions that the offer includes not only products, but also values ethical value. In pursuing this objective, retailers generate a convergence between their needs, those of small suppliers of the South, and those of 'responsible' consumers.

In the future, large retailers can play an important role in the development of a more equal and fair international trade, through the introduction of new methodologies and criteria in managing supply network in which smaller suppliers are involved. The introduction of fair trade product lines as an advanced stage of CSR for retailers can also improve the international supply network but will require a corresponding increasing sensitivity to the demand for a higher level of information that will help consumers to differentiate between effective fair trade networks and those that are only formal 'window dressing' actions.

Long-term sustainability of retailers' CSR initiatives (even from an economic point of view), combined with consumers' wider consciousness of CSR issues, can support the development of a cultural change as a basis for more balanced relationships between small manufacturers from the South and large global retailers.

\section{Bibliography}

Alexander A., Nicholls A., Rediscovering Consumer-Producer Involvement: A network Perspective on Fair Trade Marketing, European Journal of Marketing; vol. 40, n. 11/12, 2006, pp. 1236-1253. http://dx.doi.org/10.1108/03090560610702795

Arbuthnot J.J., Identifying Ethical Problems Confronting Small Retail Buyers During the Merchandise Buying Processes, Journal of Business Ethics, vol. 16, 1997, pp. 745-755. http://dx.doi.org/10.1023/A:1017999710172

Balabanis G., Phillips H., Lyall J., Corporate Social Responsibility and Economic Performance in top British Companies: Are They Linked?, European Business Review, vol. 98, n. 1, 1998, pp. 2544.

http://dx.doi.org/10.1108/09555349810195529

Carter C. R., Ethical Issues in International Buyer-Supplier Relationships: a Dyadic Examination, Journal of Operation Management, vol. 18, 2000, pp. 191-208. http://dx.doi.org/10.1016/S0272-6963(99)00016-9

Caselli L., La ri-legittimazione sociale dell'impresa, Sinergie, n. 61-62, 2003, pp. 117-131.

Dagnoli J., Consciously green, Advertising Age, vol. 14, 1991, pp. 41.

Dickerson K. G., Dalecki M., 'Apparel Manufacturers' Perceptions of Supplier-Retailer Relationships, Clothing and Textiles Research Journal, vol. 9, n. 3, 1991, pp. 7-14. http://dx.doi.org/10.1177/0887302X9100900302

Dubinsky A.J., Gwinn J.M., Business Ethics: Buyer and Seller, Journal of Purchasing and Materials Management, vol. 17, n. 4, 1981, pp. 9-16.

Eurostaf, Le développement durable dans la distribution, Eurostaf, Paris, 2001.

Gereffi G., Humphrey J., Sturgeon T., The Governance of Global Value Chain, Review of International Political Economy, vol. 12, n. 1, 2005. http://dx.doi.org/10.1080/09692290500049805

Mamic I., Managing Gloal Supply Chain: The Sports Footwear, Apparel and retail Sectors, Journal of Business Ethics, vol. 59, 2005, pp. 81-100. 
http://dx.doi.org/10.1007/s10551-005-3415-y

Harrison R., Newholm T., Shaw D., The Ethical Consumer, Sage, London, 2005.

Hemingway C.A., Maclagan P.W., Managers Personal Values as Drivers of Corporate Social Responsibility, Journal of Business Ethics, vol. 50, n.1, 2004, pp. 33-44. http://dx.doi.org/10.1023/B:BUSI.0000020964.80208.c9

Jones P., Comfort D., Eastwood I., Retailers and Sustainable Development in the UK, International Journal of Retail \& Distribution Management; vol. 33, n.3, 2005.

Logsdon J.M., Wood D.J, Global Business Citizenship and Voluntary Codes of Ethical Conduct, Journal of Business Ethics, vol. 59, n. 1-2, 2005, pp. 55-67 http://dx.doi.org/10.1007/s10551-005-3411-2

Macchiette B., Roy A., Sensitive Groups and Social Issues. Are You Marketing Correct?, Journal of Consumer Marketing, vol. 11, n. 4, 1994, pp. 55-64. http://dx.doi.org/10.1108/07363769410070890

Maignan I., Ferrel O.C. Corporate Social Responsibility and Marketing: An Integrative Framework, Journal of the Academy of Marketing Science, vol. 32, n. 1, 2004, pp. 3-19. http://dx.doi.org/10.1177/0092070303258971

Maloni, M.J; Brown M.E., Corporate Social Responsibility in the Supply Chain: An Application in the Food Industry, Journal of Business Ethics, vol. 68, n. 1, 2006, pp. 35-52. http://dx.doi.org/10.1007/s10551-006-9038-0

Musso F., Relazioni di canale e strategie di acquisto delle imprese commerciali, Edizioni Lint, Trieste, 1999.

Nicholls A., Strategic Options in Fair Trade Retailing, International Journal of Retail \& Distribution Management, vol. 30, n. 1, 2002, pp.6-17. http://dx.doi.org/10.1108/09590550210415220

Nicholls A., Fair Trade New Product Development, Service Industries Journal, vol. 24, n. 2, 2004, pp. $102-$ 117. http://dx.doi.org/10.1080/02642060412331301282

Park H., Stoel L., A Model of Social Responsible Buying/Sourcing Decision-Making Processes, International Journal of Retail \& Distribution Management; vol. 33, n. 4, 2005, pp. 235-248. http://dx.doi.org/10.1108/09590550510593176

Pepe C., Global Retailers and Corporate Responsibility, Symphonya. Emerging Issues in Management (symphonya.unimib.it), n. 1, 2003.

http://dx.doi.org/10.4468/2003.1.06pepe

Pepe C., Musso F., Economie distrettuali e canali di distribuzione all'estero, Aspi/Ins-Edit, Genova, 2000.

Piacentini M., MacFadyen L., Eadie D., Corporate Social Responsibility in Food Retailing, International Journal of Retail \& Distribution Management, vol. 28, n. 11, 2000, pp. 459-69.

Redelius W., Bucholz R.A., What Industrial Purchasers See as Key Ethical Dilemmas, Journal of Purchasing and Materials Management, vol. 15, n. 4, 1979, pp. 2-10.

Roberts S., Supply Chain Specific? Understanding the Patchy Success of Ethical Sourcing Initiatives, Journal of Business Ethics, vol. 44, n. 2-3, 2003, pp. 159-170. http://dx.doi.org/10.1023/A:1023395631811

Shaw D. Clarke I., Culture, Consumption and Choice: Towards a Conceptual Relationship Journal of Consumer Studies and Home Economics, vol. 22, n. 3, 1998, pp. 163-168. http://dx.doi.org/10.1111/j.1470-6431.1998.tb00727.x

Shaw D., Shui E., Ethics in consumer choice: a multivariate modelling approach, European Journal of Marketing, vol. 37, n. 10, 2003, pp. 1485-1498. 
Shaw D., Clarke, I., Belief Formation in Ethical Consumer Groups: An Exploratory Study, Marketing Intelligence and Planning, vol. 17, n. 2-3, 1999, pp. 109-19.

Strong. C., Features Contributing to the Growth of Ethical Consumerism - A Preliminary Investigation, Marketing Intelligence and Planning, vol. 14, n. 5, 1996, pp. 5-13. http://dx.doi.org/10.1108/02634509610127518

Trawick F., Swan J.E., Rink D.R., Back-Door Selling: Violation of Cultural Versus Professional Ethics by Salespeople and Purchasers Choice of the Supplier, Journal of Business Research, vol. 17, 1988, pp. 299-309. http://dx.doi.org/10.1016/0148-2963(88)90061-6

Whysall, P., Addressing Ethical Issues in Retailing: a Stakeholder Perspective, International Review of Retail Distribution and Consumer Research, vol. 10, n. 3, 2000, pp. 305-18. http://dx.doi.org/10.1080/095939600405992

Wood G., Ethics at the Purchaising/Sales Interface: an International Perspective, International Marketing Review, vol. 12, n. 4, 1995, pp. 7-19. http://dx.doi.org/10.1108/02651339510097702

\section{Notes}

${ }^{1}$ FLO is an international body for certification of Fair Trade products. Through a certification system, it plays a controlling role by verifying manufacturers, importers and processing companies to ensure that products with the Fair Trade mark are in accordance with the standards of fair trade.

${ }^{2}$ ATOs (Alternative Trade Organizations) are import agencies of fair trade goods, operating according to the principles and rules of fair trade. 